\title{
Distal myotilinopathy
}

INSERM

\section{Source}

INSERM. (1999). Orphanet: an online rare disease and orphan drug data base. Distal myotilinopathy. ORPHA:98911

Distal myotilinopathy is a rare, late adult-onset myofibrillar myopathy characterized by progressive distal muscle weakness associated with peripheral neuropathy and hyporeflexia. Ambulation may be lost within a few years. 